\title{
IMPLICAÇÕES DAS CONDIÇÕES DE TRABALHO NA PRÁTICA PEDAGÓGICA DE PROFESSORES DE EDUCAÇÃO FÍSICA INICIANTES NA EDUCAÇÃO BÁSICA
}

\section{HUGO NORBERTO KRUG ${ }^{1}$, MARILIA DE ROSSO KRUG ${ }^{2}$, RODRIGO DE ROSSO KRUG ${ }^{3}$, MOANE MARCHESAN KRUG ${ }^{4}$.}

\begin{abstract}
1 Doutor em Educação pela UNICAMP/UFSM; Doutor em Ciência do Movimento Humano pela UFSM; Professor Aposentado do Departamento de Metodologia do Ensino do Centro de Educação da Universidade Federal de Santa Maria pela UFSM. hnkrug@bol.com.br.

2 Doutora em Educação em Ciências: Quimica da Vida e Saúde pela UFSM; Professora do Programa de Pós-Graduação no Mestrado em Atenção Integral à Saúde da Universidade de Cruz Alta (UNICRUZ). mkrug@unicruz.edu.br.

3 Doutor em Ciências Médica pela UFSC; Professor do Programa de Pós-Graduação em Atenção Integral à Saúde no Mestrado da Universidade de Cruz Alta (UNICRUZ). rodkrug@bol.com.br.

4 Doutora em Educação Física pela UFSC; Professora do Departamento de Humanidades e Educação da Universidade Regional do Noroeste do Estado do Rio Grande do Sul pela UNIJUI. Professora Tutora do Programa de Pós-Graduação Multidisciplinar em Saúde da Família da UNIJUÍ. moane.krug@unijui.edu.br.
\end{abstract}

\section{RESUMO}

O estudo objetivou analisar as implicações das condições de trabalho na prática pedagógica de professores de Educação Física (EF) iniciantes na Educação Básica (EB), de uma rede pública de ensino, de uma cidade do interior do estado do Rio Grande do Sul (Brasil). A pesquisa caracterizou-se como qualitativa do tipo estudo de caso. O instrumento para a coleta de informações foi um questionário, sendo a interpretação efetuada por meio da análise de conteúdo. Participaram cinco professores de EF iniciantes na EB das referidas redes de ensino e cidade. Concluímos que as implicações das condições de trabalho na prática pedagógica dos professores de EF iniciantes na EB estudados compõem um cenário de precarização do trabalho docente, tendo efeitos negativos sobre a profissão professor.

Palavras-chave: Educação Física; Professores Iniciantes; Condições de Trabalho.

\section{IMPLICATIONS OF WORK CONDITIONS IN THE PEDAGOGICAL PRACTICE OF BEGINNERS PHYSICAL EDUCATION TEACHERS OF THE BASIC EDUCATION}

\begin{abstract}
The study aimed to analyze the implications of work conditions in the pedagogical practice of beginners Physical Education (PE) teachers in Basic Education (BE), in a public education network in a city in the state of Rio Grande do Sul (Brazil). The research was characterized as a qualitative case study. The instrument for collecting
\end{abstract}


information was a questionnaire, being the interpretation was carried out through content analysis. Participated five beginners PE teachers in the BE from the education netowork and city referred. We conclude that the implications of work conditions in the pedagogical practice of beginners PE teachers in the BE studied, make up a scenario of precarious teaching, with negative effects on the teaching profession.

Keywords: Physical Education; Beginners Teachers; Work conditions.

\section{INTRODUÇÃO}

Segundo Krug et al. (2019a, p. 23), é “[...] importante destacar que em tempos recentes, pesquisas sobre o início da docência em Educação Física (EF) vêm ganhando espaço nos periódicos nacionais [...]" e, nesse contexto, apontamos as seguintes investigações: Conceição et al. (2014); Medeiros et al. (2014); Conceição et al. (2015); Quadros, L. et al. (2015); Quadros, Z. et al. (2015); Santos et al. (2016); Krug (2017a); Krug et al. (2017a); Krug et al. (2017b); e, Krug et al. (2019a).

Entretanto, de acordo com Krug et al. (2019a, p. 23), “[...] mesmo diante deste cenário de intensificação de investigações [...]”, conforme Rezer; Madela e Dan-Cin (2016, p. 65), “[o] ingresso na carreira docente representa um tema complexo, ainda com muito a ser pesquisado [...]".

Neste cenário, citamos Huberman (1995), que afirma que o início na carreira docente ou fase de indução é o período que marca a entrada no campo profissional, ou seja, na escola, após a conclusão da formação inicial, compreendendo os três primeiros anos de exercício. O autor destaca que o início da carreira docente é caracterizado por dois estágios: a) a sobrevivência, que traduz o 'choque do real', isto é, de um período em que o professor se depara com a situação real do trabalho, com toda a sua complexidade e desafios e passa a perceber a distância entre o idealizado enquanto estudante no curso de formação inicial e a realidade da atividade que deverá realizar na escola e na sala de aula; e, b) a descoberta, que é caracterizada pelo entusiasmo inicial, a experimentação, o orgulho de ter a sua própria profissão e fazer parte de uma classe trabalhadora.

Diante desse cenário, emergiu o tema 'as implicações das condições de trabalho na prática pedagógica de professores de EF iniciantes na EB', pois, segundo Santos et al. (2016, p. 32), na fase de início da docência, “[...] grande parte dos professores passa por momentos difíceis, angustiantes [...]". Nesse sentido, Rezer; Madela e Dal-Cin 
(2016, p. 66) afirmam que "[...] o ingresso na carreira docente se constitui como espaço e tempo de provação que, sem dúvida, irá se desdobrar em influências das mais diversas ao longo de toda carrreira docente do professor". Além disso, Huberman (2013) descreve a fase de início da docência como problemática, pois o professor iniciante passa a se deparar com experiências que podem traumatizar e/ou entusiasmar, podendo ocasionar o abandono da profissão e/ou a confirmação do ser professor. Já Príncepe e André $(2018$, p. 4) destacam que "[u]m dos aspectos silenciados $\mathrm{n}[\mathrm{a}] \mathrm{s}$ pesquisas diz respeito às condições de trabalho na fase de indução [...]".

Assim, no direcionamento do tema deste estudo, consideramos necessários três tipos de esclarecimentos: um a respeito do que são implicações, outro sobre condições de trabalho e mais outro, relativamente à prática pedagógica.

Inicialmente, convém lembramos que, para Luft (2000), a palavra implicações significa complicações, embirrações, encadeamentos. Implicações é sinônimo de consequência que é um termo que caracteriza o resultado, reação ou efeito produzido de um acontecimento ou uma ação. Assim, para este estudo, implicações significam as complicações, os encadeamentos, ou ainda as consequências que as condições de trabalho podem produzir na prática pedagógica dos professores de EF iniciantes na EB.

Já sobre condições de trabalho, convém destacarmos que, na literatura especializada, aparecem várias definições a este respeito. Vejamos algumas a seguir.

De acordo com Oliveira e Assunção (2010, p. [s.n.]), as condições de trabalho são definidas como:

[o] conjunto de recursos que possibilitam a realização do trabalho, envolvendo as instalações físicas, os materiais e insumos disponíveis, os equipamentos e meios de realização de atividades e outros tipos de apoio necessários dependendo da natureza da produção. [...]. As condições de trabalho se referem a um conjunto que inclui relações, as quais dizem respeito ao processo de trabalho e às condições de emprego (formas de contratação, remuneração, carreira e estabilidade).

Já, Silva e Guillo (2015, p. 2) definem condições de trabalho como:

[...] o conjunto de recursos que possibilitam a realização do trabalho, envolvendo as instalações físicas, materiais e meios de realização das atividades. Refere-se também a um conjunto que inclui relações, as quais dizem respeito ao processo de trabalho e às condições de emprego [...]. Contudo, as condições de trabalho não se restringem ao plano do posto ou do local de trabalho ou à realização em si do processo de trabalho, mas diz respeito às relações de emprego. 
Entretanto, Krug (2017b, p. 5) é mais explícito ao colocar que as condições de trabalho dos professores de EF na EB possuem as seguintes facetas:

\begin{abstract}
[...] as condições de emprego (a forma de contratação, o salário, a carga horária de trabalho e de ensino com os alunos, o tamanho das turmas de alunos, a rotatividade (itinerância dos professores pelas escolas e a carreira docente), as condições de instalações físicas e materiais, a gestão da organização escolar e a organização do ensino.
\end{abstract}

Mas, o que é prática pedagógica?

Conforme Cunha (1992), a prática pedagógica é o cotidiano do professor na preparação e execução do ensino. Nesse sentido, Carreiro da Costa (1988) destaca que a prática pedagógica dos professores de EF é um problema central na ação educativa, que não pode ser realizada em si, mas como expressão de um longo processo que materializa as várias opções tomadas pelo docente durante a organização do ensino.

Nesse cenário, lembramos Gonçalves (1992) ao afirmar que a função do professor subentende ensinar, isto é, transmitir conhecimentos específicos e diversificados aos alunos, organizar o trabalho em aula, manter a disciplina, estabelecer relações com as pessoas, ter um papel de educador junto aos alunos e, ainda, promover a animação das atividades etc., o que implica o surgimento de dificuldades na prática docente que são geradas antes, durante e depois das aulas.

Dessa forma, segundo Cunha (1992), estudar o que acontece nas aulas é tarefa daqueles que se encontram envolvidos e comprometidos com uma prática pedagógica de qualidade. Já Conceição et al. (2004) colocam que o estudo sobre as práticas pedagógicas dos professores pode significar importantes veios para a formação profissional, tanto inicial, quanto continuada.

Assim, embasando-nos nestas premissas descritas anteriormente, surgiu a questão problemática, norteadora do estudo: quais são as implicações das condições de trabalho na prática pedagógica de professores de EF iniciantes na $\mathrm{EB}$, de uma rede pública de ensino, de uma cidade do interior do estado do Rio Grande do Sul-RS (Brasil)? A partir dessa indagação, o objetivo geral do estudo foi analisar as implicações das condições de trabalho na prática pedagógica de professores de EF iniciantes na EB, de uma rede pública de ensino, de uma cidade do interior do estado do RS (Brasil).

Para facilitar o alcance do objetivo geral, este estudo foi dividido em objetivos específicos: 1) analisar as implicações das condições de trabalho (as formas de 
contratação, o salário, a carga horária de trabalho e de ensino com os alunos, o tamanho das turmas de alunos, a rotatividade/itinerância dos professores pelas escolas e a carreira docente) na prática pedagógica de professores de EF iniciantes na EB, de uma rede pública de ensino, de uma cidade do interior do estado do RS (Brasil); 2) analisar as implicações das condições das instalações físicas e materiais na prática pedagógica de professores de EF iniciantes na EB, de uma rede pública de ensino, de uma cidade do interior do estado do RS (Brasil); 3) analisar as implicações das condições de gestão da organização escolar na prática pedagógica de professores de EF iniciantes na EB, de uma rede pública de ensino, de uma cidade do interior do estado do RS (Brasil); e, 4) analisar as implicações das condições de organização do ensino na prática pedagógica de professores de EF iniciantes na EB, de uma rede pública de ensino, de uma cidade do interior do estado do RS (Brasil).

Justificamos a importância da realização deste estudo devido a sua contribuição na compreensão da realidade das condições de trabalho de professores de EF iniciantes na EB.

\section{OS PROCEDIMENTOS METODOLÓGICOS}

Os procedimentos metodológicos empregados nesta investigação foram caracterizados como uma pesquisa qualitativa do tipo estudo de caso.

Conforme Bodgan e Biklen (1994, p. 13), a pesquisa qualitativa "[...] envolve a obtenção de dados descritivos, obtidos no contato direto do pesquisador com a situação estudada, enfatiza mais o processo do que o produto e se preocupa em retratar a perspectiva dos participantes”. Para Alves-Mazzotti (2006), o estudo de caso é o tipo de pesquisa desenvolvido em apenas uma unidade (por exemplo, uma instituição de ensino, uma rede de ensino etc.) ou que apresenta um número reduzido de sujeitos, sem explicitar porque foi escolhida aquela unidade e não outra, deixando a impressão de que poderia ser qualquer uma.

Assim, neste estudo, o caso investigado referiu-se aos professores de EF iniciantes na $\mathrm{EB}$, de uma cidade do interior do estado do RS (Brasil).

Dessa forma, a justificativa da escolha da forma de pesquisa qualitativa e estudo de caso foi devido "[...] à possibilidade de se analisar um ambiente em particular, onde 
se levou em conta o contexto social e sua complexidade para compreender e retratar uma realidade em particular um fenômeno em especial [...]" (KRUG et al., 2019b, p. 227), 'as implicações das condições de trabalho na prática pedagógica de professores de EF iniciantes na EB'.

$\mathrm{O}$ instrumento de pesquisa foi um questionário com perguntas abertas que versaram sobre os objetivos específicos do estudo. Justificamos a escolha desse instrumento de pesquisa fundamentando-nos em Aragão e Moretti-Pires (2012) que afirmam que o questionário é um instrumento que pode ser utilizado, tanto na pesquisa quantitativa, quanto na qualitativa. Já sobre perguntas abertas, Sampierre; Collado e Lucio (2006) dizem que são úteis quando se tem informações sobre as possíveis respostas das pessoas ou ainda quando se deseja aprofundar sobre uma opinião ou motivos de um comportamento.

A interpretação das informações coletadas pelo instrumento de pesquisa foi realizada por meio da análise de conteúdo, que, segundo Cortes (1998, p. 29), “[...] tem como pressuposto fundamental categorizar, visando identificar (ou construir) estruturas para a elaboração de modelos”. Para Bardin (2011, p. 147),

\footnotetext{
[a] categorização é uma operação de classificação de elementos constitutivos de um conjunto por diferenciação e, em seguida, por agrupamento segundo o gênero (analogia), com os critérios previamente definidos. As categorias são rubricas ou classes, as quais reúnem um grupo de elementos (unidades de registro, no caso da análise de conteúdo) sob um título genérico, agrupamento esse efetuado em razão das características comuns destes elementos.
}

Já Minayo (2002) destaca que as categorias podem ser geradas previamente à pesquisa de campo. Assim, foram consideradas como categorias prévias, as condições de emprego (as formas de contratação; o salário; a carga horária de trabalho e de ensino com os alunos; o tamanho das turmas dos alunos; a rotatividade/itinerância dos professores pelas escolas; a carreira docente); as instalações físicas e materiais; as condições de organização do ensino, isto é, os objetivos específicos do estudo. Entretanto, a partir das respostas dos participantes ao instrumento de pesquisa, foram levantadas as unidades de registro, considerando os pontos singulares e comuns sobre os elementos que correspondiam ao objeto do estudo. 
Participaram do estudo cinco professores de EF iniciantes na EB, sendo dois do 'sexo masculino' e três do 'sexo feminino', de uma rede pública de ensino, de uma cidade do interior do estado do RS (Brasil). Entretanto, o sexo dos colaboradores não foi objeto dessa investigação. Já a 'faixa etária' dos colaboradores variou 'de vinte e quatro à vinte e oito anos'. Convém destacar que consideramos iniciantes aqueles que possuíam até três anos de docência na escola, conforme Huberman (2013).

A escolha dos participantes aconteceu de forma intencional e todos assinaram o Termo de Consentimento Livre e Esclarecido e suas identidades foram preservadas (numerados de 1 à 5).

A respeito da quantidade de participantes, embasamo-nos em Deslandes (2002, p. 43) que, ao definir a amostragem de uma pesquisa, afirma que

\begin{abstract}
[a] pesquisa qualitativa não se baseia no critério numérico para garantir sua representatividade. Uma pergunta importante neste item é "quais indivíduos socais têm uma vinculação mais significativa para o problema a ser investigado?" A amostragem boa é aquela que possibilita abranger a totalidade do problema investigado em suas múltiplas dimensões.
\end{abstract}

Ainda consideramos importante destacar que esses cinco professores de EF eram os únicos iniciantes das redes de ensino e cidade estudados.

\title{
3 OS RESULTADOS E AS DISCUSSÕES
}

Os resultados e as discussões foram orientados e explicitados a partir dos objetivos específicos do estudo, pois esses representaram as categorias de análise. Assim, a seguir, foi apresentado o que expuseram os professores de EF iniciantes na EB estudados, sobre a temática em questão.

\subsection{As condições de emprego}

Segundo Oliveira e Assunção (2010), as condições de emprego fazem parte das condições de trabalho, pois essas se referem à natureza da relação entre empregador (ou a empresa) e o empregado. Assim, apresentamos, uma a uma, as condições de emprego.

\subsubsection{As formas de contratação}


Relativamente às ‘formas de contratação', que, para Oliveira e Assunção (2010), é uma das condições de emprego, constatamos que a 'quase totalidade' (quatro professores: 1; 2; 3 e 5) dos professores de EF iniciantes na EB estudados manifestou ser 'contratado temporariamente' e 'um único' (professor 4) ser 'efetivo'. Nesse cenário, citamos Valle (2003) que diz que a carreira docente, em especial do magistério público, apresenta como uma das características básicas a seleção de seus profissionais por meio de concurso público, proporcionando efetivação e, por conseguinte, a conquista da estabilidade no posto de trabalho. Já segundo Conceição et al. (2015, p. 771), os professores em caráter temporário "[...] possuem um contrato com data de início e fim nas escolas, que é estabelecido pela instituição contratante [...]”.

Ainda, sobre às 'formas de contratação', também constatamos que os professores de EF iniciantes na EB estudados manifestaram que 'ser contratado temporariamente prejudica sua prática pedagógica' (quatro professores: $1 ; 2 ; 3$ e 5) e 'ser efetivo auxilia sua prática pedagógica' (um professor: 4). Diante desse cenário, mencionamos Conceição et al. (2015, p. 778) que afirmam que a questão da contratação temporária “[...] coloca o docente iniciante em um processo instável, pois fica a dúvida de se possuir ou não uma vaga na escola, de chegar ao final do ano e seu contrato admissional terminar [...]”. Os autores destacam que “[...] esse modelo de admissão em caráter temporário, potencializado na instabilidade e insegurança, precariza o trabalho docente e possibilita o não fortalecimento do vínculo com a cultura escolar”. Já para Valle (2003), a efetivação do professor confere-lhe status profissional e proteção pelo estatuto de funcionário público efetivo nos quadros da administração pública. Dessa forma, a efetivação consente aos docentes projetar os seus planos futuros e evitar o constante enfrentamento das incertezas do mercado de trabalho.

Frente a esse cenário descrito, podemos inferir que a forma de contratação temporária possui implicações no trabalho docente, porque pode interferir negativamente na prática pedagógica dos professores de EF iniciantes na EB estudados, ocasionando um sentimento de insatisfação com a profissão. Assim, nessa direção de inferência, apontamos Krug (2017b) que afirma que a forma de contratação dos professores pode ser uma das condições de emprego que colaboram com a precarização 
do trabalho docente em EF na $\mathrm{EB}$, principalmente, quando se trata da contratação temporária.

\subsubsection{O salário}

A respeito do 'salário', que, conforme Sampaio e Marin (2004, p. 1204), é aquele percebido pelo professor "[...] pelo tempo de dedicação às suas funções [...]", constatamos que a 'totalidade' (cinco professores: $1 ; 2 ; 3 ; 4$ e 5) dos professores de EF iniciantes na EB estudados colocaram que recebem um 'baixo salário'. Nesse cenário, reportamo-nos a Sampaio e Marin (2004, p. 1210) que ressaltam que o salário baixo "[...] incide pesadamente sobre a precarização do trabalho dos professores, pois a pauperização profissional significa pauperização da vida pessoal e suas relações entre vida pessoal e trabalho, sobretudo no que tange ao acesso a bens culturais”. Já Krug et al. (2018a, p. 32) verificaram a existência das seguintes implicações dos baixos salários para o trabalho docente em EF na EB: “[...] 1) a 'insatisfação profíssional'; 2) o 'baixo poder aquisitivo'; 3) a 'sobrecarga de trabalho'; 4) o 'abandono da docência'; 5) a 'dificuldade na busca pela formação continuada'; e, 6) a 'baixa atratividade pela Licenciatura'.

Também sobre o 'salário', ainda constatamos que os professores de EF iniciantes na EB estudados, em sua 'totalidade' (cinco professores: $1 ; 2 ; 3 ; 4$ e 5) colocaram que o 'baixo salário prejudica sua prática pedagógica'. Diante desse cenário, fundamentamo-nos em Somariva; Vasconcellos e Jesus (2013, p. 6) que destacam que o baixo salário percebido "[...] vai influenciar diretamente no trabalho do professor que, por sua vez, já chega à escola [...] insatisfeito [...]”. Assim, segundo Krug et al. (2018a, p. 30), o baixo salário “[...] interfere na qualidade do ensino [...]” da EF Escolar.

Frente a esse cenário descrito, podemos inferir que o baixo salário possui implicações no trabalho docente, porque pode interferir negativamente na prática pedagógica dos professores de EF iniciantes na EB estudados, ocasionando um sentimento de insatisfação com a profissão. Assim, nessa direção de inferência, citamos Krug et al. (2019c, p. 18) que apontam que “[o] baixo salário percebido” é um dos fatores indicativos de insatisfação profissional em todas as fases da carreira docente (entrada, estabilização, diversificação, serenidade e/ou conservantismo e 
desinvestimento) dos professores de EF da EB. Já para Krug, Krug e Telles (2018, p. 298), "o salário baixo" é um dos motivos dos desencantos com a profissão docente pelos professores de EF da EB e que estes podem levar ao absenteísmo e/ou abandono da profissão.

\subsubsection{A carga horária de trabalho e de ensino com os alunos}

Ao referirmos sobre a 'carga horária de trabalho e de ensino com os alunos', citamos Sampaio e Marin (2004) que dizem que esta é uma das facetas ligadas às condições de trabalho, e, nesse sentido, constatamos que a 'totalidade' (cinco professores: 1; 2; 3; 4 e 5) dos professores de EF iniciantes na EB estudados ressaltaram que 'possuem uma carga horária de trabalho e de ensino com os alunos na integralidade das horas de seu contrato de trabalho, sem horas destinadas para o seu estudo ou de outra natureza'. Nesse sentido, lembramos Príncepe e André (2018, p. 12) que colocam que "[a] jornada de trabalho [...] é um fator que pode facilitar ou dificultar o $\mathrm{D}$ (esenvolvimento) $\mathrm{P}$ (rofissional) dos professores e pode criar uma série de clivagens entre os docentes, pois implica formas mais ou menos atrativas e mais favoráveis ou menos favoráveis ao D(esenvolvimento) P(rofissional)" (acréscimo nosso). Entretanto, estes autores ainda dizem que

\footnotetext{
[d]adas as características do trabalho docente, além do tempo destinado às atividades específicas em sala de aula para a condução do processo de ensino dos alunos e, também, as ações que antecedem as aulas (planejamentos, estudos) e as que sucedem o tempo de sala de aula (correções, revisões, replanejamentos, atendimento aos pais e outros), não se pode considerar adequada uma jornada de trabalho que considera apenas o tempo destinado ao ensino (PRÍNCEPE; ANDRÉ, 2018, p. 12).
}

Frente a este cenário descrito, podemos inferir que uma carga horária de trabalho com os alunos na integralidade das horas de seu contrato de trabalho, sem horas destinadas para o seu estudo ou de outra natureza, é um fator negativo para o desenvolvimento profissional dos professores de EF iniciantes na EB estudados. Esse fato está em consonância com o colocado por Krug (2017b) de que uma carga horária de trabalho e de ensino com os alunos elevada é um dos indicadores da precarização do trabalho docente em EF na EB. 


\subsubsection{O tamanho das turmas de alunos}

Referentemente ao 'tamanho das turmas de alunos', que segundo Sampaio e Marin (2004, p. 1214), é “[o]utra faceta diretamente ligada às condições de trabalho [...]”, constatamos que a 'totalidade' (cinco professores: $1 ; 2 ; 3 ; 4$ e 5) dos professores de EF iniciantes na EB estudados, manifestou que a 'média de alunos nas turmas de EF foi de mais de 30'. Nesse cenário, observamos Sampaio e Marin (2004) que afirmam que, no Brasil, verifica-se uma queixa constante dos professores em geral quanto às turmas de alunos excessivamente numerosas.

Ainda sobre o 'tamanho das turmas de alunos', também constatamos que os professores de EF iniciantes na EB estudados em sua 'totalidade' (cinco professores: 1; 2; 3; 4 e 5) manifestaram que o 'número elevado de alunos nas turmas' de EF 'prejudicam sua prática pedagógica'. Diante desse cenário, referimo-nos a Krug et al. (2019b, p. 229) que constataram que "[...] o número elevado de alunos nas turmas [...]" é uma das dificuldades pedagógicas no cotidiano escolar de professores de EF da EB em diversas fases da carreira docente. Já para Krug (2019a, p. 6), são mais específicos, pois constataram que “[...] o número elevado de alunos nas turmas [...]" é uma das dificuldades encontradas na prática pedagógica de professores de EF iniciantes na EB.

Frente a esse cenário descrito, podemos inferir que o elevado número de alunos nas turmas de EF possui implicações no trabalho docente, porque pode interferir negativamente na prática pedagógica dos professores de EF iniciantes na EB estudados, ocasionando dificuldades na prática pedagógica de professores de EF na EB em geral, conforme afirmado por Krug (2019b, p. 6). Já Krug (2017b) coloca que o tamanho excessivo da turma de alunos é um dos indicadores da precarização do trabalho docente em EF na EB.

\subsubsection{A rotatividade/itinerância dos professores pelas escolas}

Quanto à 'rotatividade/itinerância dos professores pelas escolas' que, para Sampaio e Marin (2004), é mais uma outra faceta que está diretamente ligada às condições de trabalho, constatamos que a 'totalidade' (cinco professores: $1 ; 2 ; 3 ; 4$ e 5) 
dos professores de EF iniciantes na EB estudados afirmou que 'trabalham somente em uma escola'. Esse fato está em consonância com Conceição et al. (2004) que constataram em um estudo com professores de EF da EB de uma cidade do interior do estado do RS que a maioria dos pesquisados trabalhavam somente em uma escola e não costumavam trocar de escola de um ano para outro ou no mesmo ano.

Frente a este cenário descrito, podemos inferir que o fato de não haver rotatividade/itinerância dos professores pelas escolas é um fator positivo para o desenvolvimento profissional dos professores de EF iniciantes estudados. Assim, essa inferência está em consonância com o apontado por Tardif e Raymond (2000, p. 217) de que, “[...] do ponto de vista profissional e de carreira, saber como viver numa escola é tão importante quanto saber ensinar na sala de aula”. Nesse sentido, os autores colocam que, "a inserção numa carreira e seu desenrolar exigem que os professores assimilem também saberes práticos específicos aos lugares de trabalho, com suas rotinas, valores e regras" (TARDIF; LESSARD, 2005, p. 127).

\subsubsection{A carreira docente}

Em referência à 'carreira docente', citamos Sampaio e Marin (2004) que salientam que esta é também mais uma outra faceta ligada às condições de trabalho dos professores, constatamos que a 'quase totalidade' (quatro professores: 1; 2; 3 e 5) dos professores de EF iniciantes na EB estudados afirmou 'não ter direito a um plano de carreira por ser contratado temporariamente' e 'um único' (professor 4) 'sim, tem um plano de carreira', que se baseia em 'gratificações por tempo de serviço e titulação, mas que são valores irrisórios'. Nesse cenário, mencionamos Krug (2017b, p. 7) que destaca que "[..] os professores temporários logicamente não têm direito a essas gratificações, pois ao término de seu contrato são despedidos". Já Tardif (2003), diz que carreira docente é uma prática e rotina institucionalizada no campo do trabalho, identificada com o processo de socialização profissional. Nesse direcionamento de colocação, lembramos Gonçalves (1992) que destaca que a carreira dos professores desenvolve-se por referência a duas dimensões complementares: 1) a individual, centrada na natureza do seu eu, construído à nível consciente e inconsciente; e, 2) a grupal ou coletiva, 
construída sobre as representações do campo escolar, influenciando e determinando aqueles.

Frente a esse cenário descrito, podemos inferir que não ter a possibilidade de ter uma carreira docente com boas perspectivas futuras possui implicações no trabalho docente, porque pode interferir negativamente na prática pedagógica dos professores de EF iniciantes na EB estudados, ocasionando um sentimento de insatisfação com a profissão. Assim, nessa direção de inferência, apontamos Curi (2007, p. 30) que afirma que o profissional que ingressa na carreira de magistério, às vezes, "não tem muitos degraus à sua frente dentro da instituição, o que exclui mais uma forma de motivação importante para iniciar num emprego com estas condições e, principalmente, para permanecer nele ao longo dos anos”. Já segundo Krug (2017b), não possuir plano de carreira e/ou possuir plano de carreira que não motivem os profissionais a progredirem profissionalmente são indicadores da precarização do trabalho docente em EF na EB.

\subsection{As instalações físicas e materiais}

Sobre às ‘instalações físicas e materiais', que, segundo Castro (1997), são alguns dos aspectos que mostram as condições de trabalho dos professores de EF Escolar, constatamos que a 'totalidade' (cinco professores: $1 ; 2 ; 3 ; 4$ e 5) dos professores de EF iniciantes na EB estudados declarou as 'precárias condições das instalações físicas e materiais' disponíveis para o desenvolvimento das aulas de EF Escolar. Nesse cenário, referimo-nos à Krug (2017b) que concluiu que existe uma precarização do trabalho docente em EF, na rede pública de ensino, em virtude das deficientes condições de espaço físico e materiais disponíveis para a EF Escolar, entre outros aspectos.

Também sobre as 'instalações físicas e materiais', ainda constatamos que os professores de EF iniciantes na EB estudados, em sua 'totalidade' (cinco professores: 1; 2; 3; 4 e 5) declararam que as 'precárias condições das instalações físicas e materiais' disponíveis para o desenvolvimento das aulas de EF Escolar 'prejudicam sua prática pedagógica'. Diante desse cenário, observamos Krug et al. (2016a) que ressaltam que a situação de precariedade de condições das instalações físicas e materiais fazem parte da cultura da EF Escolar na EB, o que, com certeza, prejudica a qualidade do ensino desse componente curricular. Ainda no direcionamento desse cenário, reportamo-nos à 
Rebolo (2012, p. 101) que diz que a inadequação e/ou escassez de elementos relacionados às condições físicas e materiais e de infraestrutura na escola, "[...] limita a atividade docente e exige mais esforços dos professores, podendo levá-los à frustrações e desmotivação, além do esgotamento físico e psicológico”. Também Libâneo (2012) salienta que a ausência, precariedade e descaso com as condições físicas e de infraestrutura do espaço educativo influencia negativamente, tanto no trabalho do professor, quanto na aprendizagem dos alunos.

Frente a este cenário descrito, podemos inferir que as precárias condições das instalações físicas e materiais disponíveis para o desenvolvimento das aulas de EF Escolar possuem implicações no trabalho docente, porque podem interferir negativamente na prática pedagógica dos professores de EF iniciantes na EB estudados, ocasionando um sentimento de insatisfação com a profissão. Assim, nessa direção de inferência, apontamos Silva e Krug (2007) que afirmam que a falta de espaços físicos e de materiais são geradores de sentimentos de insatisfação dos professores de EF da EB para com a sua prática docente. Já Krug et al. (2019c, p. 18) colocam que "[a] falta de condições de trabalho da EF na escola", isto é, falta de espaço físico e materiais para as aulas de EF é um dos fatores indicativos de insatisfação profissional em todas as fases da carreira docente (entrada, estabilização, diversificação, serenidade e/ou conservantismo e desinvestimento) dos professores de EF da EB. Ainda Krug; Krug e Telles $(2018$, p. 297) ressaltam que "as condições de trabalho difíceis/precárias da EF na escola" é um dos motivos dos desencantos com a profissão docente pelos professores de EF da EB e que estes podem levar ao absenteísmo e/ou abandono da profissão. Assim, Krug et al. (2019a, p. 26) colocam que “[...] saber dar aula de EF em condições de trabalho difíceis/precárias" é uma das necessidades formativas de professores de EF iniciantes na EB.

\subsection{As condições de gestão da organização escolar}

À respeito das 'condições de gestão da organização escolar', conforme Tardif e Lessard (2005, p. 28), “[o] trabalho docente leva também as marcas da organização escolar [...]", constatamos que a 'totalidade' (cinco professores: 1; 2; 3; 4 e 5) dos professores de EF iniciantes na $\mathrm{EB}$ estudados manifestou que, a 'Gestão Escolar não é 
efetiva', isto é, deixa a desejar na organização escolar, sendo que esta está centralizada na administração da escola pela equipe diretiva (diretor, vice-diretor, coordenador e supervisor pedagógico), o que prejudica a qualidade da educação oferecida pela instituição escolar. Esse fato da Gestão Escolar não efetiva, está em consonância com o estudo de Krug (2017b) que concluiu que existe uma precarização do trabalho docente em EF, na rede pública de ensino, em virtude das condições não efetivas da gestão da organização escolar.

Ainda, sobre às 'condições de organização do ensino', também constatamos que os professores de EF iniciantes na EB estudados em sua 'totalidade' (cinco professores: $1 ; 2 ; 3 ; 4$ e 5) colocaram que 'a Gestão Escolar não efetiva prejudica sua prática pedagógica'. Assim, no direcionamento desse fato, Volpato et al. (2011) dizem que a Gestão Escolar influi diretamente no desempenho e no grau de satisfação dos professores com o trabalho docente, portanto, uma má gestão é uma fonte de insatisfação dos professores na escola e uma boa gestão é, ao contrário, uma fonte de satisfação dos professores na escola.

Frente a esse cenário, podemos inferir que as condições de gestão da organização escolar, isto é, a Gestão Escolar não efetiva, possui implicações no trabalho docente, principalmente, porque pode interferir negativamente na prática pedagógica dos professores de EF iniciantes na EB estudados, ocasionando um sentimento de insatisfação com a profissão. Assim, nessa direção de inferência, citamos Ilha e Krug (2008) que afirmam que, em alguns aspectos, a realidade escolar não contribui para uma efetiva participação dos professores na gestão da escola. Já Lück (2007) acrescenta que a Gestão Escolar representa uma dimensão importantíssima na educação, uma vez que, por meio dela, observa-se a escola e seu conjunto, os problemas que, de fato, funcionam de modo interdependente.

\subsection{As condições de organização do ensino}

Em relação às 'condições de organização do ensino', segundo Tardif e Lessard (2005, p. 28), “[o] trabalho docente leva também as marcas da organização escolar [...]”, constatamos que a 'totalidade' (cinco professores: $1 ; 2 ; 3 ; 4$ e 5) dos professores de EF iniciantes na EB estudados apontou o seu 'isolamento profissional docente'. Nesse 
cenário, lembramos Würdig (1999) que alerta que a estrutura e a rotina das escolas parecem provocar o isolamento dos professores e, consequentemente, o individualismo, pois não são priorizados momentos de trocas de experiências, de organização, de planejamento e projetos coletivos, de diálogo e relatos sobre a prática pedagógica, no sentido de ampliar a formação continuada. Já Krug et al. (2016a) destacam que o isolamento docente faz parte da cultura da EF Escolar.

Também sobre às 'condições de organização do ensino', ainda constatamos que os professores de EF iniciantes na EB estudados em sua 'totalidade' (cinco professores: $1 ; 2 ; 3 ; 4$ e 5) apontaram que o seu 'isolamento profissional docente prejudica sua prática pedagógica'. Diante desse cenário, Krug et al. (2017b) afirmam que o isolamento docente é um dos desafios que se postam no cotidiano educacional para os professores de EF iniciantes na EB. Já Quadros, L. et al. (2015) enfatizam que a falta de apoio e auxílio da organização escolar, ou seja, o isolamento docente é um dos problemas da prática pedagógica dos professores de EF iniciantes na EB. Ainda abordando esta situação, mencionamos Silveira et al. (2008, p. 66) que colocam que "[o] fato do professor de EF iniciante ter ou não uma participação mais (coletiva) no contexto escolar influencia na forma como a disciplina de EF é tratada pelos outros professores, logo, na possibilidade da legitimação dessa disciplina, bem como na socialização e no respeito do próprio professor no âmbito escolar" (inserção nossa). No que concerne à socialização do professor em início da carreira, Santos et al. (2016) dizem que consiste em fazer com que os professores novatos aprendam e interiorizem as normas, valores e condutas que caracterizam a cultura escolar a qual estão inseridos. Também sobre essa situação, é importante destacar que, segundo Silva (1997), a falta de apoio no ambiente escolar torna ainda mais difícil o processo de iniciação na docência. Já Krug (1996) destaca que não se chega a um bom resultado no ensino da EF com professores numa posição de individualismo e de isolamento profissional.

Frente a esse cenário, podemos inferir que no contexto das condições de organização do ensino, o isolamento profissional docente possui implicações no trabalho, porque pode interferir negativamente na prática pedagógica dos professores de EF iniciantes na EB estudados, ocasionando um sentimento de insatisfação com a profissão. Assim, nessa direção de inferência, lembramos Krug (2017b) que destaca que o trabalho de forma isolada, enquanto uma das condições do ensino faz parte da 
precarização do trabalho docente em EF na EB. Nesse sentido, segundo Krug et al. (2019a, p. 27), “[...] compreender as causas e as consequências do isolamento docente” é uma das necessidades formativas do professor de EF iniciantes na EB.

\section{AS CONSIDERAÇÕES CONCLUSIVAS}

Neste momento, consideramos necessário mencionar que este estudo assumiu como objetivo geral analisar as implicações das condições de trabalho na prática pedagógica de professores de EF iniciantes na EB, de uma rede pública de ensino, de uma cidade do interior do estado do RS (Brasil) e agora explicaremos o seu desenrolar.

Quanto às condições de emprego dos professores, constatamos que: a) 'a quase totalidade (quatro) é contratada temporariamente e somente um é efetivo'; b) 'a totalidade (cinco) recebe um salário baixo’; c) 'a totalidade (cinco) possui carga horária de trabalho integral de aulas a serem ministradas, sem horas para outras tarefas como estudos e planejamento de ensino'; d) 'a totalidade (cinco) possui turmas com número elevado de alunos'; e) 'a totalidade (cinco) trabalha somente em uma escola'; e, f) 'a quase totalidade (quatro) diz não ter direito a um plano de carreira por ser contratado temporariamente e somente um diz possui um plano de carreira que se baseia em gratificações por tempo de serviço e titulação, mas com valores irrisórios'. Assim, esse cenário das condições de emprego dos professores estudados revelam uma precarização do trabalho docente em EF na EB.

Quanto às instalações físicas e materiais para o trabalho dos professores, constatamos que, 'a totalidade (cinco) possui precárias instalações físicas e materiais para o desenvolvimento das aulas de EF na escola'. Dessa forma, as instalações físicas e materiais visivelmente revelam uma precariedade do trabalho docente em EF na EB.

Quanto às condições de gestão da organização escolar, constatamos que, 'a totalidade (cinco) avalia a Gestão Escolar como não efetiva, isto é, deixa a desejar na organização escolar’. Nesse sentido, as condições de gestão da organização escolar revelam uma limitação na forma de favorecer um bom desenvolvimento profissional dos docentes e, consequentemente, na qualidade do ensino proporcionado aos alunos de EF na EB.

Quanto às condições de organização do ensino pelos professores, constatamos que, 'a totalidade (cinco) declarou que, trabalha de forma isolada, individualizada, sem 
trabalho coletivo'. Diante desse quadro, podemos afirmar que as condições de organização do ensino pelos docentes revelam uma situação que prejudica a qualidade do ensino proporcionado aos alunos de EF na EB.

Assim, tendo em vista o que constatamos neste estudo, concluímos que 'as implicações das condições de trabalho na prática pedagógica dos professores de EF iniciantes na EB estudados compõem um cenário de precarização do trabalho docente, tendo efeitos negativos sobre a profissão professor'.

Nesse sentido, para reforçarmos os achados deste estudo, citamos Codo (1999) que, tempos atrás, já manifestava que, no Brasil, as condições de trabalho dos docentes eram precárias, pois, o salário é baixo, faltam recursos financeiros, é fraca a perspectiva de progressão na carreira, etc. Dessa forma, salientamos que decorridas mais de duas décadas, a situação continua a mesma para o professorado brasileiro. Então, diante deste quadro, Krug (2019b, p. 9) destaca que “[...] tendo em vista as questões organizacionais, tudo que a escola fornece ao trabalhador a coloca como uma das piores organizações para se trabalhar". É um quadro de precarização do trabalho docente que concorre para afastar, cada vez mais, os jovens da carreira docente, pois não lhes oferece atrativos. Já Krug e Krug (2020) constataram que o início da carreira é gerador de atratividade para a permanência na docência em EF na $E B$, bem como da não atratividade pela permanência na docência em EF na EB e que este fato perpassa por motivos fortemente enraizados na realidade atual da profissão professor, e, isto, mostra-se independentemente da fase da carreira a qual estão vivenciando.

Assim, frente aos resultados alcançados por este estudo, sugerimos a necessidade de discussões mais aprofundadas sobre as implicações das condições de trabalho na prática pedagógica de professores de EF na EB não somente de iniciantes, mas em todas as fases da carreira docente.

\section{REFERÊNCIAS}

ALVES-MAZZOTTI, A. J. Usos e abusos dos estudos de caso. Cadernos de Pesquisa, São Paulo, v. 36, n. 129, p. 637-651, 2006.

ARAGÃO, P.; MORETTI-PIRES, R. O. Questionários. In: SANTOS, S. G. dos; MORETTI-PIRES, R. O. (Orgs.). Métodos e técnicas de pesquisa qualitativa aplicada à Educação Física. Florianópolis: Tribo da Ilha, 2012. 
BARDIN, L. Análise de conteúdo. São Paulo: Edições 70, 2011.

BOGDAN, R.; BIKLEN, S. Fundamentos da investigação qualitativa em educação: uma introdução. In: BOGDAN, R.; BIKLEN, S. Investigação qualitativa em educação. Porto: Porto Editora, 1994.

CARREIRO DA COSTA, F. A. A. Sucesso pedagógico em Educação Física: estudo das condições e fatores de ensino-aprendizagem associados ao êxito numa unidade de ensino, 1988. Tese (Doutorado em Ciência da Motricidade Humana) - Universidade Técnica de Lisboa, Lisboa, 1988.

CASTRO, W. L. de. Educação Física Escolar: as idéias e a realidade da escola. In: ENCONTRO FLUMINENSE DE EDUCAÇÃO FÍSICA ESCOLAR, II., 1997, Niterói. Anais, Niterói: Universidade Federal Fluminense, 1997.

CODO, W. (Org.). Educação: carinho e trabalho. Petrópolis: Vozes/Brasília: Confederação Nacional dos Trabalhadores em Educação; Universidade de Brasília, Laboratório de Psicologia do Trabalho, 1999.

CONCEIÇÃO, V. J. S. da et al. O perfil do professor de Educação Física do Ensino Fundamental em Santa Maria (RS). In: SIMPÓSIO NACIONALDE EDUCAÇÃO FÍSICA, XXIII., 2004, Pelotas. Anais, Pelotas: ESEF/UFPel, 2004. CD-ROOM.

CONCEIÇÃO, V. J. S. da; KRUG, H. N.; BOROWSKI, E. B. V.; FRASSON, J. S. Formação inicial e a prática pedagógica do professor de Educação Física iniciante. Revista Olhar de Professor, Ponta Grossa, v. 17, n. 1, p. 86-97, 2014.

CONCEIÇÃO, V. J. S. da; FRASSON, J. S.; MEDEIROS, C. da R.; WITTIZORECKI, E. S.; KRUG, H. N. A organização escolar e o trabalho docente de professores iniciantes de Educação Física de Criciúma-SC. Revista Pensar a Prática, Goiânia, v. 18, n. 4, p. 769-781, out./dez. 2015.

CORTES, S. M. V. Técnicas de coleta e análise qualitativa de dados. In: NEVES, C. E. B.; CORRÊA, M. B. (Orgs.). Pesquisa social empírica: métodos e técnicas. Porto Alegre: Programa de Pós-Graduação em Sociologia, Universidade Federal do Rio Grande do Sul, 1998. p. 11-47.

CUNHA, M. I. da. O bom professor e sua prática. 6. ed. Campinas: Papirus, 1992.

CURI, F. Professor sob pressão. Revista Educação, São Paulo, a. 10, n. 119, p. 30-36, mar. 2007.

DESLANDES, S. F. A construção do projeto de pesquisa. In: MINAYO, M. C. de S. (Org.). Pesquisa social: teoria, método e criatividade. 21. ed. Petrópolis: Vozes, 2002. p. 31-50.

GONÇALVES, J. A. A carreira dos professores do Ensino Primário. In: NÓVOA, A. (Org.). Vidas de professores. 2. ed. Porto: Porto Editora, 1995. p. 141-170. 
HUBERMAN, M. O ciclo de vida profissional dos professores. IN: NÓVOA, A. (Org.). Vidas de professores. 2. ed. Porto: Porto Editora, 1995. p. 31-61.

ILHA, F. R. da S.; KRUG, H. N. O professor de Educação Física e sua atuação como gestor. Revista Digital Lecturas: Educación Física y Deportes, Buenos Aires, a. 13, n. 125, p. 1-10, set. 2008. Disponível em: http://www.efdeportes.com/efd125/oprofessor-de-educacao-fisica-como-gesto... . Acesso em: 24 mar. 2020.

KRUG, H. N. A reflexão na prática pedagógica do professor de Educação Física, 1996. Dissertação (Mestrado em Ciência do Movimento Humano) - Universidade Federal de Santa Maria, Santa Maria, 1996.

KRUG, H. N. Comparação das dificuldades encontradas na prática pedagógica em Educação Física de acadêmicos em situação de Estágio Curricular Supervisionado e professores iniciantes na Educação Básica. Revista Gestão Universitária, Belo Horizonte, p. 1-13, nov. 2017a. Disponível em: http://www.gestaouniversitaria.com.br/artigos/comparacao-das-dificuldadesencontradas-na-pratica-pedagogica-em-educacao-fisica-de-academi... . Acesso em: 02 set. 2019.

KRUG, H. N. A precarização do trabalho docente em Educação Física na Educação Básica. Revista Gestão Universitária, Belo Horizonte, p. 1-12, nov. 2017b. Disponível em: http://www.gestaouniversitaria.com.br/artigos/a-precarizacao-do-trabalho-docenteem-educacao-fisica-na-educacao-basica.htm. Acesso em: 02. set. 2019.

KRUG, H. N.; KRUG, R. de R.; TELLES, C. Encantos e desencantos na profissão de professores de Educação Física na Educação Básica. Revista Textura/ULBRA, Canoas, v. 20, n. 44, p. 289-306, set./dez. 2018.

KRUG, H. N.; KRUG, R. de R.; TELLES, C.; CONCEIÇÃO, V. J. S. da. A cultura da Educação Física Escolar. Revista Temas em Educação, João Pessoa, v. 25, n. 1, p. 6177, jan./jun. 2016a.

KRUG, H. N.; KRUG, M. de R.; KRUG, R. de R.; TELlES, C.; FLORES, P. P. As contribuições da formação inicial para a prática docente na percepção de professores de Educação Física iniciantes na Educação Básica. Revista Querubim, Niterói, a. 13, n. 33, v. 02, p. 104-109, 2017a.

KRUG, H. N.; KRUG, M. de R.; KRUG, R. de R.; TELLES, C.; FLORES, P. P. Os desafios do cotidiano educacional de professores de Educação Física iniciantes na Educação Básica. Revista Didática Sistêmica, Rio Grande, v. 19, n. 2, p. 14-28, 2017 b.

KRUG, H. N.; KRUG, R. de R.; KRUG, M. de R.; TELLES, C.; FLORES, P. P. As marcas docentes no início da carreira de professores de Educação Física na Educação Básica. Revista Triângulo, Uberaba, v. 10, n. 1, p. 56-72, jan./jun. 2017 ac. 
KRUG, H. N.; KRUG, M. de R.; KRUG, R. de R.; TELlES, C.; FLORES, P. P. A representação social de si mesmo e da profissão docente de professores de Educação Física iniciantes na Educação Básica. Revista Estudos Aplicados em Educação, São Caetano do Sul, v. 2, n. 4, p. 49-63, jul./dez. 2017d.

KRUG, H. N.; KRUG, M. de R.; KRUG, R. de R.; KRUG, M. M.; TELLES, C. Implicações dos baixos salários para o trabalho docente na percepção de professores de Educação Física da Educação Básica. Revista Querubim, Niterói, a. 14, n. 36, v. 03, p. 28-34, 2018a.

KRUG, H. N.; KRUG, M. de R.; KRUG, R. de R.; KRUG, M. M.; TELLES, C. Os desafios docentes no cotidiano educacional em diferentes fases da carreira de professores de Educação Física da Educação Básica. Revista Querubim, Niterói, a. 15, n. 37, v. 4, p. 33-41, 2018a.

KRUG, H. N.; KRUG, M. de R.; KRUG, R. de R.; KRUG, M. M.; TELLES, C. Necessidades formativas de professores de Educação Física iniciantes na Educação Básica. Revista Querubim, Niterói, a. 15, n. 38, v. 4, p. 23-31, 2019a.

KRUG, H. N.; KRUG, R. de R.; KRUG, M. de M.; KRUG, M. M.; TELLES, C. As dificuldades pedagógicas no cotidiano educacional em diferentes fases da carreira de professores de Educação Física da Educação Básica. Horizontes - Revista de Educação, Dourados, v. 7, n. 13, p. 223-246, jan./jun. 2019b.

KRUG, H. N.; KRUG, M. de R; KRUG, R. de R.; KRUG, M. M.; TELLES, C. A docência em Educação Física na Educação Básica: os fatores indicativos de (in)satisfação profissional em diferentes fases da carreira. Revista Querubim, Niterói, a. 15 , n. 38 , v. 4, p. 13-22, 2019c.

LIBÂNEO, J. C. Educação escolar: políticas, estrutura e organização. São Paulo: Cortez, 2012.

LÜCK, H. Gestão educacional: uma questão paradigmática. 3. ed. Petrópolis: Vozes, 2007.

LUFT, C. P. MiniDicionário Luft. São Paulo: Ática/Scipione, 2000.

MEDEIROS, C. da R.; BOROWSKI, E. B. V.; KRUG, H. N.; CONCEIÇÃO, V. J. S. da. Identização docente de professores de Educação Física no início da carreira. Revista Educação em Perspectiva, Viçosa, v. 5, n. 2, p. 31-49, jul./dez. 2014.

OLIVEIRA, D. A.; ASSUNÇÃO, A. A. Condições de trabalho docente. In: OLIVEIRA, A. M. C.; VIEIRA, L. M. F. Dicionário: trabalho, profissão e condição docente. Belo Horizonte: Universidade Federal de Minas Gerais/Faculdade de Educação, 2010.

PRÍNCEPE, L.; ANDRÉ, M. E. D. A. de. Fatores facilitadores e dificultadores do desenvolvimento de professores iniciantes: uma análise das condições de trabalho. 
Revista Estudos Aplicados em Educação, São Caetano do Sul, v. 3, n. 6, p. 1-15, jul./dez. 2018.

QUADROS, L. R. de; CARDOSO, V. D.; FRASSON, J. S.; MEDEIROS, C. da R.; BOROWSKI, E. B. V.; CONCEIÇÃO, V. J. S. da; KRUG, H. N. O trabalho docente de professores de Educação Física iniciantes do município de Criciúma-SC. Revista Conexões, Campinas, v. 13, n. 3, p. 12-23, jul./set. 2015.

QUADROS, Z. de F.; BLASIUS, J.; KRUG, H. N.; CONCEIÇÃO, V. J. S. da. Prática educativa de professores de Educação Física no início da docência. Revista Educação \& Linguagem, São Paulo, v. 18, n. 1, p. 21-40, jan./jun. 2015.

REBOLO, F. Fontes e dinâmicas do bem-estar docente: os quatro componentes de um trabalho felicitário. In: REBOLO, F.; TEIXEIRA, L. R. B.; PERRELLI, M. A. S. (Orgs.). Docência em questão: discutindo trabalho e formação. Campinas: Mercado de Letras, 2012. p. 23-60.

REZER, R.; MADELA, A.; DAL-CIN, J. Apontamentos sobre o ingresso na carreira docente: possibilidades para o campo da Educação Física. In: CONCEIÇÃO, V. J. S. da; FRASSON, J. S. (Orgs.). Textos e contextos sobre o trabalho do professor de Educação Física no início da docência. Porto Alegre: Sulina, 2016. p. 65-84.

SAMPAIO, M. das M. F.; MARIN, A. J. Precarização do trabalho docente e seus efeitos sobre as práticas curriculares. Revista Educação e Sociedade, Campinas, v. 25, n. 89, p. 1203-1225, set./dez. 2004.

SAMPIERI, R. H.; COLLADO, C. F.; LUCIO, M. del P. B. Metodologia da pesquisa. São Paulo: McGraw Hill, 2006.

SANTOS, M. dos; CONCEIÇÃO, V. J. S. da; FRASSON, J. S.; KRUG, H. N. Dificuldades pedagógicas encontradas por professores de Educação Física no início da docência. Revista Querubim, Niterói, a. 12, n. 28, v. 03, p. 32-38, 2016.

SILVA, M. C. M. O primeiro ano da docência: o choque com a realidade. Lisboa: Porto Editora, 1997.

SILVA, M. S. da; KRUG, H. N. Os sentimentos satisfação e insatisfação dos professores de Educação Física. Revista Digital Lecturas: Educación Física y Deportes, Buenos Aires, a. 12, n. 115, p. 1-8, dic. 2007. Disponível em: http://www.efdeportes.com/efd115/satisfacao-e-insatisfacao-dos-professores-deeducacao-fisica.htm . Acesso em: 02 set. 2019.

SILVA, R. A. O.; GUILlO, L. A. Trabalho docente e saúde: um estudo com professores da Educação Básica do sudeste goiano. Revista Itinerarius Reflectionis, Jataí, v. 11, n. 2, p. 1-17, 2015.

SILVEIRA, J. da S.; MASCHIO, V.; BASEI, A. P.; SILVA, M. S. da; KRUG, H. N. O desenvolvimento profissional dos professores de Educação Física: o início da docência. 
In: KRUG, H. N.; KRÜGER, L. G.; CRISTINO, A. P. da R. (Orgs.). Os professores de Educação Física em formação. Santa Maria: Universidade Federal de Santa Maria, Centro de Educação, Programa de Pós-Graduação em Educação, 2008. p. 63-67. (Coleção Formação de Professores de Educação Física; v. 4).

SOMARIVA, J. F. G.; VASCONCELLOS, D. I. R.; JESUS, T. V. de. As dificuldades enfrentadas pelos professores de Educação Física das escolas públicas do município de Braço Norte. In: SIMPÓSIO SOBRE FORMAÇÃO DE PROFESSORES (SIMFOP), V., 2013, Tubarão. Anais, Tubarão, 2013. p. 1-14.

TARDIF, M. Saberes docentes e formação profissional. Petrópolis: Vozes, 2003.

TARDIF, M.; LESSARD, C. O trabalho docente: elementos para uma nova teoria da docência como profissão de interações humanas. Tradução de João Batista Krench. Petrópolis: Vozes, 2005.

TARDIF, M.; RAYMOND, D. Saberes, tempo e aprendizagem do trabalho no magistério. Revista Educação \& Sociedade, Campinas, a. 21, n. 73, p. 209-244, 2000.

VALLE, I. R. A era da profissionalização: formação e socialização do corpo docente de $1^{\mathrm{a}}$ a $4^{\mathrm{a}}$ série. Florianópolis: Cidade Futura, 2003.

VOLPATO, G.; BAUMER, E. R.; AZEREDO, J. L. de; DOMINGUINI, L. Desafios da profissão e problemas na formação do professor na percepção de acadêmicos de Artes Visuais e Matemática. Revista Educação em Perspectiva, Viçosa, v. 2, n. 2, p. 223 245, jul.dez, 2011.

WÜRDIG, R. C. Dos bancos universitários aos pátios escolares: da formação inicial à prática pedagógica dos professores de Educação Física. In: VERONEZ, L. F.; MENDEZ, V. (Orgs.). XVIII Simpósio Nacional de Educação Física. Coletânea de Textos e Resumos. Pelotas: UFPel, 1999. 